\title{
THE DEVELOPMENT OF A NEW DEVICE-SYSTEM FOR VISUAL INSPECTIONS OF INFUSION PUMPS
}

\author{
LEKSCHA, Thomas] \& DURACKOVA, D[aniela]
}

\begin{abstract}
The paper presents the most important results of the investigative work and subsequent developments leading to a new device concept for medical technology. It particularly applies to visual inspections of different infusion pumps. The aim of this work was to develop a new device-system for detecting visible defects which could influence the safe operation of infusion pumps and thereby minimize the risks in the application of automated infusion systems.

Keywords: Infusion pump, visual inspection, medical device, Medical Devices Operator Ordinance
\end{abstract}

\section{INTRODUCTION}

Today, automated infusion systems are indispensable and routinely used in clinics for the parenteral infusion of fluid substances into the blood circulation of the human body. Infusion therapy plays an important role during the treatment of patients. Almost $90 \%$ of all patients who undergo stationary treatment receive infusion solutions [1]. More than 600 million infusion solutions flow into the veins of patients every year [2].

Infusion therapy, supported by medical technology, is used whenever the mechanisms in the metabolism of the human body have become unbalanced. Infusion therapy enables maintaining, correcting and substituting the necessary quantities of substances in the body. Infusion systems are used, for example, to compensate for dehydration, normalize the electrolyte metabolism, maintain the acid-base balance and to administer drugs. Automated infusion systems enable the infusion of fluids at specific rates, certain quantities and in different types of application.

The administration of fluids by means of automated systems, however, is not possible without a certain amount of risk as far as the technical equipment is concerned. The increasing use of technology in medicine requires new approaches when discussing the technical safety and user skills required for medical equipment.

This document describes the development of a new device-system for aiding the visual inspection of infusion pumps before using them for medical purposes. The new technical concept is basically composed of two modules. One module relates to the handheld or operating unit, used to control the inspections, and is carried constantly by the infusion pump operator, generally nursing staff. The other module is designed as a switch box and is assigned to a specific type of infusion pump. The newly developed device-system has the following advantages and innovations to improve the current state of affairs:
- Guidance through visual inspections via software and hardware components,

- Support for the visual inspection through easy menu navigation,

- Recognition of technical errors prior to starting up,

- Minimising oversights,

- Recording of individual visual inspections and later recall for analysis, as necessary.

\section{LEGAL REQUIREMENTS}

All infusion pumps must be subjected to a visual inspection each time before they are started up. The aim of the visual inspection is to detect any visible defects which could influence the safe operation of an infusion pump. The legal foundation is provided directly in the Medical Devices Operator Ordinance, §2, Subitem 5 [3]. Citation: "Der Anwender hat sich vor der Anwendung eines Medizinproduktes von der Funktionsfähigkeit und dem ordnungsgemäßen Zustand des Medizinproduktes zu überzeugen $[\ldots]$ " ("The user must verify the functional capability and proper condition of the medical device before putting it into operation [...]"). (Federal Law Gazette 2009, Page 2326). An indirect instruction can be found in the Medical Devices Act. §4, Subitem 1/1 [4]. Citation: "Es ist verboten, Medizinprodukte in Verkehr $\mathrm{zu}$ bringen, zu errichten, in Betrieb zu nehmen, zu betreiben oder anzuwenden, wenn [...] die Gesundheit der Patienten, der Anwender oder Dritter bei sachgemäßer Anwendung [...] unmittelbar oder mittelbar gefährden [...]" ("It is forbidden to introduce, set up, operate or use medical devices when $[\ldots]$ the health of the patient, user or third party could be in direct or indirect danger when used properly [...]"). (Federal Law Gazette 2011, Page 2178).

Verification or evidence of completion of the legally recommended "visual inspection" is not explicitly required or prescribed. If a technical error occurs on an infusion pump which leads to the injury or even death of a patient, the operator of an infusion pump cannot currently prove that the required preliminary visual inspection was, in fact, performed prior to use.

Documentation of the visual inspection is neither required nor completed to date. The new technical concept, the newly developed device-system provides an initial approach to providing evidence of the recommended visual inspection.

- Fulfilment of legal requirements, 


\section{OPERATING PANEL}

The operating panel, which represents the mobile input device, is equipped with an analogue resistive touch screen (Fig. 1). The resistive touch screen has the advantage that its technical construction also enables it to be operated while wearing gloves. This was a major consideration for selecting the touch screen during the development phase of the device. Since infusion pump operators (nursing staff) normally wear protective gloves when using one, operation of the handheld unit must fulfil this condition. The technical design of the analogue resistive screen enables operation while wearing gloves because the input and response to questions posed is only possible through finger pressure (Fig. 2).

After the decision regarding the hardware for the analogue resistive touch screen had been made, the most important operating levels and contact surfaces were defined for the handheld unit. The laboratory sample of the handheld unit is composed of the following operating levels:

- Hardware Initialization,

- Main Menu,

- Adjustment,

- Documentation,

- Visual Check,

- Error Indication.

The most important level for the nursing staff, the operator, is the "Visual Check" level. A process describing the procedure for completing a visual inspection of an infusion pump was conceived and drafted. It was compiled following the review of several operating manuals for infusion pumps currently in use, from various manufacturers, employing differing feed mechanisms, the intension being to ensure all the relevant information would be taken into account. The computer-assisted aspect of the visual inspection of an infusion pump involved the compilation of a series of questions for the operator to answer aimed at gaining information on the properties of an infusion pump's housing, screen display, plugs, sockets etc., as well as questions on the self-test (Fig. 2). When the questions have been answered by the operator and the answers evaluated by the software provide positive results, the infusion pump is activated for operation via a Bluetooth signal. In the event of a negative evaluation of the answers, information is displayed on clearing the error.

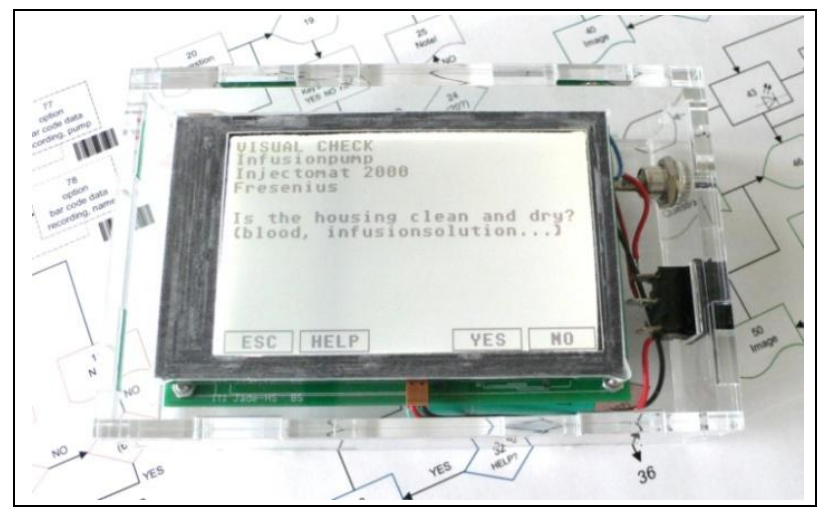

Fig. 1. Prototype of the operating unit implementing an analogue resistive touch screen

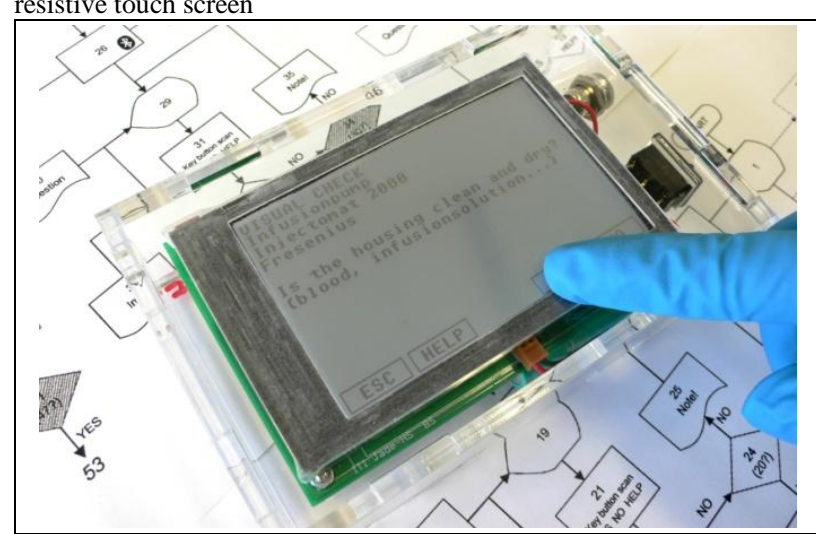

Fig. 2. Menu navigation (Question/Answer) on the analogue resistive touch screen wearing insulating medical gloves

\section{SWITCH BOX}

The switch box integrated in the newly developed system must be positioned near the infusion pump used. Since communication between the operating unit and switch box is performed via Bluetooth, a distance of $5 \mathrm{~m}$ between them has been considered suitable. The switch box switches the necessary power supply for the infusion pump on or off. It is controlled by the operating unit described above according to the analysis of the answers to the questions in respect of the visual inspection.

Since the switch box (Fig. 5) is to be used to control a technical medical device, special requirements were defined regarding the construction based on requirements stipulated in directives for medical products. For reasons of functional safety, the switch box is equipped with redundant function modules (relays) which activate a second logical sequence should a logical sequence fail, thus ensuring trouble-free operation. A microcontroller [5] monitors the switch status of the relays in the switch box, monitors the Bluetooth module and activates of the visual and acoustic alarms at the respective intervals (Fig. 3).

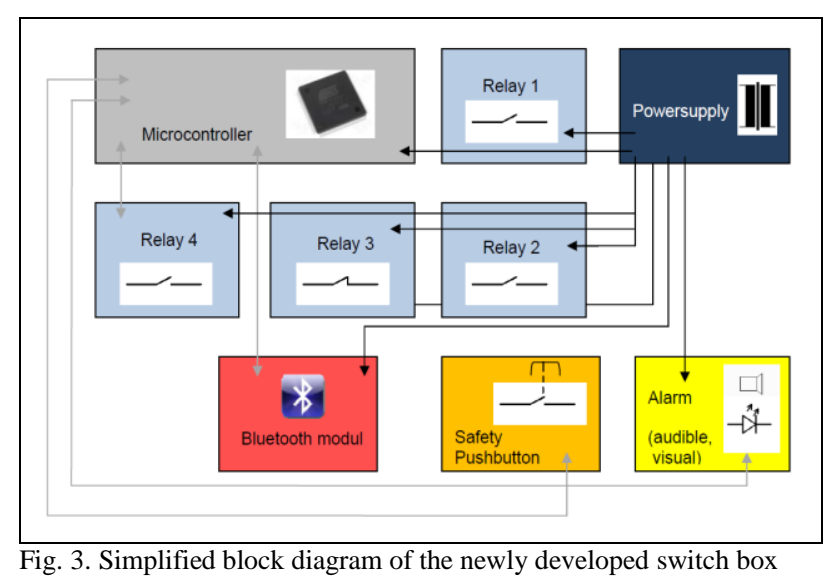
prototype

The assignment of the operating unit to the switch box is performed via the Bluetooth interface, or rather its coding. These rules out the possibility of intervention by another Bluetooth transmitter not specifically assigned to the system. The initialisation of the power-up and 
shutdown routines for the power supply are also realised via a Bluetooth signal (Fig. 4).

The same type of Bluetooth module was used in both components, namely the handheld unit with operating panel and the switch box. A commonly used, wellconceived Bluetooth module, the "BTM-222" from Rayson Technology Co., Ltd., was installed. The module implements Version 2.0+ EDR (Enhanced Data Rate) technology and has a transmission rate of $2.1 \mathrm{Mbit} / \mathrm{s}$ [6].

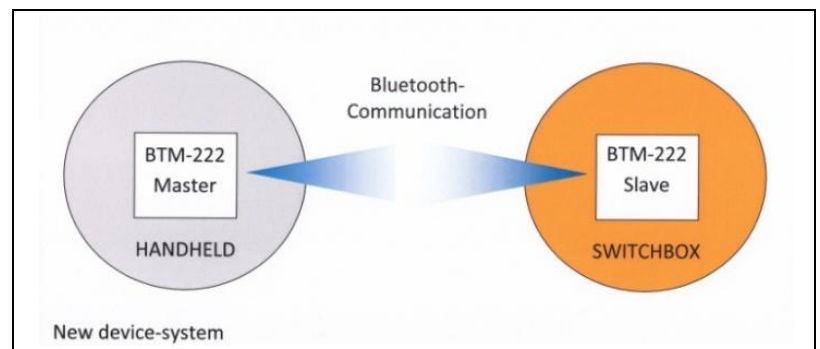

Fig. 4. Simplified block diagram of the communication between the handheld unit and switch box

The use of Bluetooth technology in medical devices has been tested and validated by a wide variety of applications. Within the scope of orthopaedic technology, Bluetooth equipment is used to configure and adjust artificial limbs. Some hearing aids are equipped with Bluetooth receivers. The uploading and downloading of data from blood glucose monitoring devices, respiratory equipment and defibrillators is performed today, in the main, via reliable Bluetooth connections.

The application examples mentioned above have been validated through the implementation of approval procedures in compliance with the Medical Product Act and is considered as being safe for the European market. The experience gained in respect of the safe use of Bluetooth technology within medical engineering was a major reason for implementing this technology in the newly developed system.

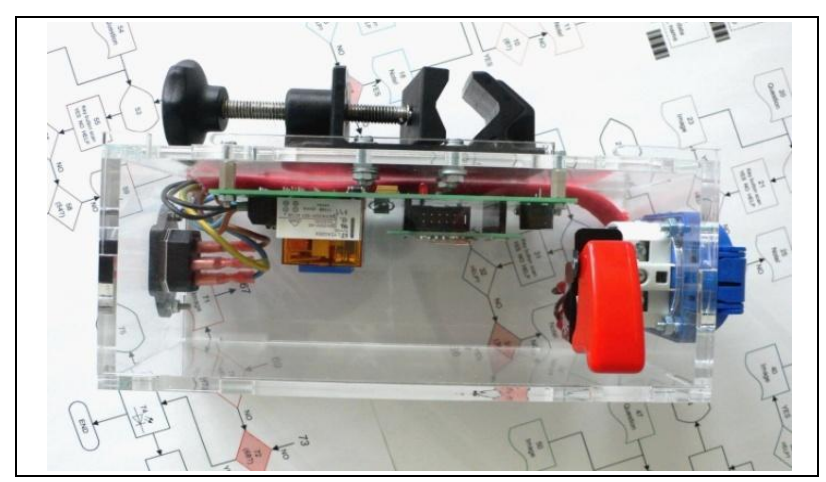

Fig. 5. Switch box prototype

\section{LABORATORY TESTS}

The newly developed system, consisting of handheld unit with operating panel and switch box, currently exists as a laboratory sample or prototype. Both units are still in the test phase. This test phase is being used to examine and verify the electro technical functionality, handling and use of the units in practice and the simplicity with which the instructions and questions (appearing in the display) can be understood and acted upon by nursingstaff.

Within the scope of the laboratory test phase, any deficiencies should be detected and eliminated. The results of this test phase will enable the man-machine interface, or rather the interoperation of nursing staff and devices, to be optimised. The aspect of safe handling and use of the equipment in medical rooms was determined and realised by practical experimentation and application at laboratory scale. The series of laboratory tests were completed under very realistic conditions in the medical technology laboratory at the Jade University in Germany (Fig. 6).

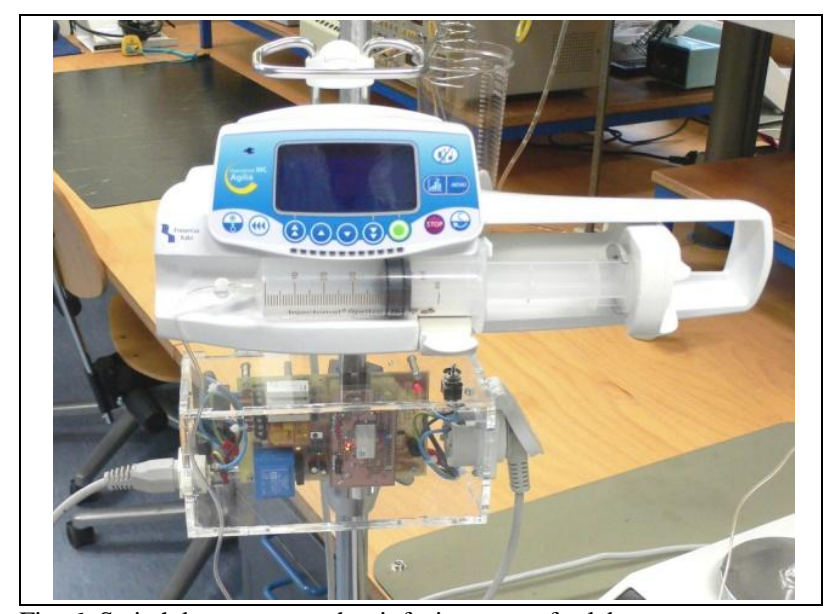

Fig. 6. Switch box connected to infusion pump for laboratory use

The tests were performed by students from the Medical Engineering and Media Science Departments (Fig. 7). All the students, including those from the nonspecialist Department of Media Science, were capable of operating the system after a short introductory session. According to the students, the operator guidance (in the display) was comprehensible and clear. Since the operator guidance is dependent on the type of infusion pump used, the period required for training can vary.

The way in which the new system can be handled, and the ease with which it can be operated, will be major factors affecting acceptance of the system. The more complicated the operation, the longer the training period and, as a result, the less willingness to accept and implement the system. Further tests should be completed during the course of everyday hospital life, in daily use in hospital wards, independent of the laboratory tests.

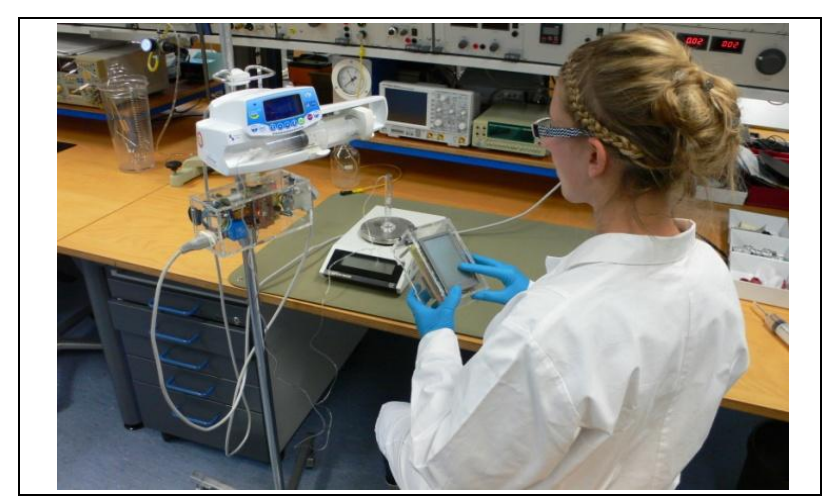

Fig. 7. Operating unit and switch box in laboratory use 


\section{CONCLUSION}

The system developed is mainly intended for use in hospitals and larger nursing homes. Legislation requires a visual inspection of an infusion pump each time before putting it into operation and, subsequently, it must be performed by nursing staff several times a day. Acceptance of using this new system depends, to a large extent, on nursing staff considering the system to be a considerable aid to completing visual inspections of various types of infusion pumps and does not represent an additional, bureaucratic and unhelpful procedure which increases the workload.

Furthermore, each visual inspection completed will be documented by the system. The documentation represents a safeguard for personnel in respect of their employer or hospital management and the legislator.

Potential users of such a system are mainly nursing staff and medical personnel in hospitals. The latest survey completed by the German Federal Statistical Office from November 2011 established 2064 hospitals in Germany. These hospitals employed 306.213 persons as nursing staff and 134.847 persons as medical staff [7]. This results in a total of over 440.000 potential users in Germany alone. The high number underlines the necessity and level of importance of the newly developed system.

The new system provides support for the visual inspections prescribed by law which stipulates that an infusion pump must undergo a visual check each time before being activated. The term visual inspection of infusion pumps in itself implies the sources of errors which should be minimised or prevented by the newly developed devices.

At present, the units making up the system only exist as functional laboratory models. It is envisaged to develop the system further and eventually go into series production. The resourceful nature and innovation of the system are also reflected by the registration of a patent. The patent application has been submitted to the German Patent and Trademark Office and is registered under the preliminary Application Number 102012002847.4 [8].

The introduction of a new system of technical units to support the visual inspection of infusion pumps is envisaged for 2013. It is hoped to present the new system at the MEDICA 2013, the world's largest exhibition of medical devices and medicine in Düsseldorf, Germany.

A reduction in the size of the handheld unit, which represents the input unit, is possible by adaptation and/or use of proven mobile computer systems already on the market. Handheld units using operating systems such as Android, Symbian and others would be available. The use of such proven systems would not only allow a considerable reduction in the size of the handheld units and to optimise them, but also simplify development aimed at designing a device for series production.

\section{ACKNOWLEDGEMENTS}

We would like to thank the Faculty of Engineering Science at the Jade University in Wilhelmshaven, Germany, and the Faculty of Electrical Engineering and Information Technology at the Slovak University of Technology in Bratislava, Slovakia for their support in realizing this project. Further thanks must go to the State of Lower Saxony, Germany, and the European Union for partial financing of the project.

\section{AUTORS}

Thomas Lekscha received his Dipl.-Ing. from the Faculty of Engineering Science, Jade University in Wilhelmshaven, Germany, and his M.Sc. from the Faculty of Electrical Engineering and Information Technology, Slovak University of Technology in Bratislava. He is currently working toward the Ph.D. degree at the Faculty of Electrical Engineering and Information Technology, Slovak University of Technology in Bratislava. He is a Member of a research staff for medical technology at the Department of Medical Technology, Jade University, Germany.

Daniela Durackova received her M.Sc. from the Faculty of Engineering and Information Technology, Slovak University of Technology in Bratislava. She received her Ph.D. from the same University. Prof. Durackova is a head of VLSI group in the Institute of Electronics and Photonics. Her research activities are from biomedical applications of neural networks to VLSI design.

\section{REFERENCES}

[1] B. Braun Melsungen AG: Infusion- and Transfusion devices, Onlinepublication, http://www.bbraun.de/cps/rde/xchg/bbraun-de/ hs.xsl/ products.html? level=1\&id $=00020741570002085860$, current access 27.03.2012

[2] Alter, U., Braun Melsungen AG: Healthcare Journal 02/10, Page 1, Melsungen, Germany 2010

[3] Federal Ministry of Justice: Medical Products User Regulation MPBetreibV, Federal Law Gazette I, No. 48, Page 2326, Revised Issue 31.07.2009

[4] Federal Ministry of Justice: Medical Products Act MPG, Federal Law Gazette I, No. 57, Page 2178, Revised Issue 11.11.2011

[5] Atmel Corporation: ATmega1284P, Datasheet, Page 3, Number 8059D-AVR-11/09, Atmel Corporation, 2009

[6] Rayson Technology Co., Ltd.: Bluetooth Module BTM-222 Datasheet. Onlinepublication http://www.bexpro-shop.de/media/ files_public/ jxgdqxyg wel/BTM222 DataSheet.pdf, current access 28.03.2012

[7] Statistical Federal Office: Health, basic data oft he hospitals, Issue 12, Edition 6.1.1, 2010, No. 2120611107004, Statistical Federal Office, Wiesbaden, Germany, 2012

[8] Lekscha, Th; Weinert, J.: Systems for the Switching of Infusion pumps and Procedure to their Initiation. Reference number 10 2012, 002 847.4, Patent Applikation 22.03.2012, German Patent and Trademark Office, Munich, Germany, 2012 